\title{
PENGARUH PEMANFAATAN INTERNET DAN MOTIVASI BELAJAR \\ TERHADAP HASIL BELAJAR SISWA KELAS VII DI SMP NEGERI 1 \\ KAPONGAN TAHUN PELAJARAN 2015/2016
}

\author{
Rizka Mahendra Putra \\ STKIP PGRI Situbondo \\ rizka0708068906@stkippgri-situbondo
}

\begin{abstract}
ABSTRAK
Hasil belajar yang dicapai siswa berbeda-beda, ada siswa yang berprestasi tinggi, sedang, dan ada pula siswa yang berprestasi rendah. Hal ini tentu saja dipengaruhi oleh berbagai macam faktor, baik faktor intern (berasal dari dalam siswa itu sendiri) maupun faktor ekstern (berasal dari luar siswa itu sendiri). Faktor yang mempengaruhi prestasi belajar siswa timbul dari dalam dan luar diri siswa adalah motivasi belajar dan cara belajar siswa. Kebiasaan atau sesuatu yang dilakukan secara berulang-ulang merupakan suatu cara bertindak yang telah dikuasai, diuji, seragam, dan berlaku secara otomatis tanpa dipikirkan lagi, yang dapat mempengaruhi tujuan siswa untuk mencapai hasil belajar yang diinginkan. Penelitian ini bertujuan untuk mengetahui apakah ada pengaruh pemanfaatan internet dan motivasi belajar terhadap hasil belajar siswa kelas VII SMP Negeri 1 Kapongan Kabupaten Situbondo. Penelitian ini merupakan penelitian kuantitatif. Metode pengumpulan data adalah kuisioner, tes, dan dokumentasi. Subjek penelitian ini adalah siswa kelas VII dengan jumlah populasi 127 responden dengan menggunakan metode random sampling maka diambil sebanyak 100 responden. Analisis data menggunakan analisis korelasi dan analisis regresi berganda. Uji hipotesis untuk mengetahui pengaruh kemandirian belajar, dan lingkungan belajar diketahui $\mathrm{F}$ reg sebesar 34,052. Sedangkan $F$ tabel yaitu sebesar 3,96 dengan taraf signifikansi 5\%. Dari perhitungan tersebut, harga $F$ reg sebesar 34,052 lebih besar dari pada $F$ tabel dengan taraf signifikansi $5 \%$ sebesar 3,96. Jadi F reg > F table yang berarti hipotesis nol ditolak dan hipotesis alternatif diterima. Hal ini menunjukkan bahwa
\end{abstract}


hipotesis alternatif (Ha) diterima dan hipotesa nol (Ho) ditolak. Hipotesa Alternatif yang diterima adalah "ada pengaruh signifikan yang sangat kuat antara pemanfaatan internet, motivasi intrinsik dan motivasi ekstrinsik secara bersama-sama terhadap hasil belajar siswa SMP Negeri 1 Kapongan tahun pelajaran 2015/2016. Untuk R Square didapatkan 51,553\%. Dari perhitungan analisis tersebut dapat diketahui bahwa motivasi ekstrinsik lebih besar dari pada variabel yang lain yaitu memberikan pengaruh sebesar $33,598 \%$ terhadap hasil belajar siswa. Pengaruh motivasi intrinsik sebesar $23,117 \%$, sedangkan pemanfaatan internet memberikan sumbangan sebesar 17,975 .

Kata Kunci : Pemanfaatan Internet, Motivasi Intrinsik, Motivasi Ekstrinsik, Hasil Belajar

\begin{abstract}
Student learning outcomes are achieved vary, there are students who are high achievers, medium, and there are also students who are underachieving. This is of course influenced by various factors, both internal factors (derived from the students themselves) as well as external factors (derived from outside the students themselves). Factors that affect student achievement arise from within and outside the student is learning motivation and learning styles of students. Habit or something that is done repeatedly is a way of acting that has been mastered, tested, uniform, and applies automatically without thinking anymore, which can affect students' goals to achieve the desired learning outcomes. This study aims to determine whether there is influence of the use of the internet and motivation toward learning outcomes seventh grade students of SMP Negeri 1 Kapongan regency. This research is quantitative. Methods of data collection were questionnaires, tests, and documentation. The subjects were students of class VII with a population of 127 respondents using the random sampling method was taken by 100 respondents. Analysis of data using
\end{abstract}


correlation analysis and multiple regression analysis. Hypothesis test to determine the influence of independent learning, and the learning environment is known $F$ reg at 34.052. While $F$ table that is equal to 3.96 with a significance level of 5\%. From these calculations, the prices of $34.052 \mathrm{~F}$ reg greater than $F$ table the 5\% significance level of 3.96. So $F$ reg> F table which means the null hypothesis is rejected and the alternative hypothesis is accepted. This suggests that the alternative hypothesis (Ha) is accepted and the null hypothesis (Ho) is rejected. An alternative hypothesis is accepted: "There is a very strong significant effect between use of the Internet, intrinsic motivation and extrinsic motivation together on learning outcomes of students of SMP Negeri 1 Kapongan 2015/2016 school year. For $R$ Square obtained 51.553\%. From the calculation of the analysis can be seen that extrinsic motivation is greater than the other variables which give the effect of $33.598 \%$ of the student learning outcomes. Influence of intrinsic motivation of $23.117 \%$, while the use of the Internet provide a donation of 17.975 .

Keywords: Using Internet, Intrinsic Motivation, Extrinsic Motivation, Learning Outcomes 


\section{PENDAHULUAN}

\section{LATAR BELAKANG}

Belajar adalah suatu proses yang kompleks yang terjadi pada diri setiap orang sepanjang hidupnya. Proses belajar itu terjadi karena ada interaksi antara seseorang dengan lingkungan. Oleh karena itu, belajar dapat terjadi kapan saja dan dimana saja. Salah satu tanda bahwa orang itu belajar adalah adanya perubahan tingkah laku pada diri seseoarang itu yang mungkin terjadi disebabkan oleh terjadinya peningkatan minat dan semnagat belajar .

Motivasi mempunyai peranan yang cukup besar di dalam upaya belajar. Tanpa motivasi, siswa tidak mungkin melakukan kegiatan pembelajaran. Motivasi merupakan tenaga dari dalam yang menyebabkan seseorang untuk berbuat sesuatu. Energi yang di timbulkan motivasi dapat mempengaruhi gejala kejiwaan, misalnya adalah perasaan. perasaan akan timbul simpati yang menyebabkan kegiatan belajar siswa yang memiliki motivasi belajar yang kuat, kemungkinan akan dapat melakukan belajar dengan sebaikbaiknya.

Masalah pendidikan dan pengajaran merupakan masalah yang cukup kompleks di mana banyak faktor yang mempengaruhinya. Salah satu faktor tersebut adalah pendidik atau guru. Guru merupakan komponen pendidikan yang yang memegang peranan penting dan utama, karena keberhasilanproses belajar mengajar sangat ditentukan oleh faktor guru. Adapun salah satu tugas guru adalah menyampaikan materi pelajaran kepada siswa melalui interaksi komunikasi dalam proses belajar mengajar yang dilakukan. Keberhasilan guru dalam menyampaikan informasi sangat tergantung pada kelancaran interaksi komunikasi antara guru dan peserta didik. Ketidak lancaran komunikasi membawa akibat terhadap pesan yang disampaikan oleh guru. Banyak dari guru yang tidak menguasai benar komunikasi kepada muridnya sehingga apa yang disampaikan tidak bisa diterima dengan jelas, walaupun guru tersebut sudah menguasai materi yang diajarkan namun karena komunikasi tidak lancar, maka murid akan mengalami kesulitan dalam memahami materi yang disampaikan oleh gurunya.

Internet di bidang pendidikan sangat berguna dalam proses belajar mengajar di sekolah, dimana para siswa dapat melengkapi ilmu pengetahuannya, sedangkan guru dapat mencari bahan ajar yang sesuai dan inovatif melalui internet. Murid dapat mencari apa saja di Internet, mulai dari mata pelajaran hingga ilmu pengetahuan umum semuanya bias di cari di internet. Sedangkan guru bisa mencari informasi yang dapat dijadikan bahan untuk mengajarkan materi kepada siswanya selain dari buku.

Penggunaan Internet sebagai media pendidikan dapat dianggap sebagai suatu hal yang sudah jamak digunakan di kalangan pelajar. Untuk itu sekolah-sekolah bisa menjadikan Internet sebagai sarana untuk belajar selain dari bukku dan agat mampu menjadi solusi dalam mengatasi masalah yang selama ini terjadi, misalnya minimnya buku yang ada di perpustakaan, keterbatasan tenaga ahli, jarak rumah dengan lembaga 
pendidkan, biaya yang tinggi dan waktu belajar yang terbatas. Menyadari bahwa di Internet dapat ditemukan berbagai informasi apa saja, maka pemanfaatan Internet menjadi suatu kebutuhan.

Melihat latar belakang masalah tersebut diatas, maka penulis bermaksud mengadakan penelitian dengan judul "Pengaruh pemanfaatan internet dan motivasi belajar terhadap hasil belajar siswa kelas VII di SMP Negeri 1 Kapongan tahun pelajaran 2015/2016".

\section{Rumusan Masalah}

Berdasarkan latar belakang masalah diatas, maka peneliti merumuskan masalah sebagai berikut:

\section{a. Mayor}

Adakah Pengaruh pemanfaatan internet dan motivasi belajar terhadap hasil belajar siswa kelas VII di SMP Negeri 1 Kapongan tahun pelajaran 2015/2016?

\section{b. Minor}

1. Adakah pengaruh motivasi belajar Intrinsik terhadap hasil belajar siswa kelas VII di SMP Negeri 1 Kapongan tahun pelajaran 2015/2016?

2. Adakah pengaruh motivasi belajar Ektrinsik terhadap hasil belajar siswa kelas VII di SMP Negeri 1 Kapongan tahun pelajaran 2015/2016?

3. Adakah Pengaruh pemanfaatan internet terhadap hasil belajar siswa kelas VII di SMP Negeri 1 Kapongan tahun pelajaran 2015/2016?

\section{METODE PENELITIAN}

\section{Lokasi dan Waktu Penelitian}

Penelitian ini akan dilaksanakan di SMP Negeri 1 Kapongan yang berada di Kecamatan Kapongan Kabupaten Situbondo. Kelas yang dipilih pada penelitian ini yaitu kelas VII.

\section{Desain Penelitian}

Dalam penelitian ini menggunakan pendekatan kuantitatif dan metode rancangan penelitian yang digunakan adalah rancangan Ex Post Facto.

\section{Variabel Penelitian}

Variabel penelitian ini adalah motivasi belajar $\left(\mathrm{X}_{1}\right)$ dan penggunaan internet $\left(\mathrm{X}_{2}\right)$ 
sebagai variabel bebas. Sedangkan hasil belajar siswa (Y) sebagai variabel terikat.

\section{Populasi}

Populasi adalah wilayah generalisasi yang terdiri atas: obyek/subyek yang mempunyai kualitas dan karakteristik tertentu yang ditetapkan oleh peneliti untuk dipelajari dan kemudian ditarik kesimpulannya (Sugiyono, 2013). Populasi dalam penelitian ini adalah seluruh siswa kelas VII SMP Negeri 1 Kapongan yang berjumlah 127 orang siswa.

\section{Sampel}

Sampel merupakan bagian dari populasi yang memiliki ciri-ciri atau keadaan tertentu yang akan diteliti. Atau sampel dapat didefinisikan sebagai anggota populasi yang dipilih dengan menggunakan prosedur tertentu sehingga diharapkan mewakili populasi. Sampel yang digunakan dalam penelitian ini adalah Simple Random Sampling, merupakan teknik pengambilan sampel yang dilakukan secara acak tanpa memperhatikan strata yang ada dalam populasi tersebut.

\section{Pengumpulan Data}

\section{Tes}

Untuk mengetahui kemampuan siswa dalam memahami dan menguasai materi sebagai tolak ukur ketuntasan belajar siswa.

\section{Observasi}

Semua kegiatan yang ditujukan untuk mengenali, merekam, mendokumenta-sikan setiap indikator dari proses dan hasil yang dicapai yang ditimbulkan tindakan terencana.

\section{Dokumentasi}

Untuk mencari data mengenai hal-hal berupa catatan, transkrip buku, informasi sekolah dan data sekolah.

\section{Teknik Analisis Data}

\section{a. Analisa Regresi}

Persamaan garis regresi persamaan ini digunakan untuk menggambarkan pengaruh prediktor pengaruh penguatan terhadap kriterium berpikir kritis siswa, rumus untuk mencari persamaan garis regresi adalah:

Persamaan garis regresi tiga prediktor

$$
\mathbf{Y}=\mathbf{a}_{1} \mathbf{x}_{1}+\mathbf{a}_{2} \mathbf{x}_{2}+\mathbf{a}_{3} \mathbf{x}_{3}+K
$$




\section{b. Menghitung Korelasi}

Korelasi antara kriterium y dengan prediktor $\mathrm{x}_{1}$ dan $\mathrm{x}_{2}$. Statistik ini akan menunjukkan kepada kita apakah garis regresi yang persamaannya telah kita temukan itu cukup efektif untuk memprediksi kriterium y berdasarkan prediktor yang kita pakai rumus perhitungannya adalah sebagai berikut :

$\operatorname{Ry}(1,2,3) \sqrt{\frac{a 1 \sum x 1 y+a 2 \sum x 2+\mathrm{a} 3 \Sigma x 3 y}{\Sigma y 2}}$

Keterangan :

Ry $\left(\mathbf{1 , 2 , 3 )}\right.$ : Koefisien korelasi antara y dengan $\mathrm{x}_{1}$ dan $\mathrm{x}_{2}$

$\mathbf{a}_{1}$ : Koefisien predictor $\mathrm{x}_{1}$

$\mathbf{a}_{2}$ : Koefision Prediktor $\mathrm{x}_{2}$

$\mathbf{a}_{3}$ : Koefision Prediktor $\mathrm{x}_{3}$

$\mathbf{x}_{1} \mathbf{y}$ : Jumlah produk antara $\mathrm{x}_{1}$ dan $\mathrm{x}_{2}$

$\mathbf{x}_{2} \mathbf{y}$ : Jumlah antara $x_{2}$ dengan $x_{3}$

$\mathbf{x}_{3} \mathbf{y}$ : Jumlah antara $x_{3}$ dengan $y$

$\mathbf{y}^{2}$ : Jumlah Kuadrat kriterium y

\section{c. Menghitung Analisis Varian Garis Regresi}

Untuk mengetahui apakah Ry $(1,2,3)$ signifikan atau tidak harus dilakukan analisis varian garis regresi dengan mencari F reg.

$$
\text { F reg }=\frac{\mathrm{R}^{2}(n-m-1)}{\mathrm{m}\left(1-\mathrm{R}^{2}\right)}
$$

Keterangan :

F reg : Harga $F$ garis regresi

N : Banyaknya data

m : Jumlah predictor

R : Koefisien korelasi / Ry $(1,2,3)$ dikuadratkan 


\section{d. Efektifitas Garis Regresi}

EGR digunakan jika peneliti ingin informasi mengenai sumbangan relatif tiap predictor dari keseluruhan dengan rumus:

$$
\text { EGR }=\frac{\text { JKreg }}{\text { JKtot }} \times 100 \%
$$

Yang mana $=\quad$ Jktot $=\mathfrak{W} \mathbf{Y}^{2}$

\section{e. Sumbangan Efektif (SE)}

Sumbangan efektif adalah sumbangan prediktor yang dihitung dari keseluruhan efektifitas regresi hal ini peneliti ingin mengetahui sumbangan efektifitas tiap prediktor dari keseluruhan prediksi, maka SE\% tiap predictor harus dihitung dari persentase efektifitas garis regresi yaitu:

$$
\begin{aligned}
& \mathrm{SE}_{1} \%=\frac{\mathrm{a}_{1} \hbar \mathrm{x}_{1} \mathrm{y}}{\mathrm{JKreg}} \underset{\text { EGR }}{\mathrm{X}} \\
& \mathrm{SE}_{2} \%=\frac{\mathrm{A}_{2} \nmid x_{2} \mathrm{y}}{\text { JKreg }} \underset{\text { EGR }}{\mathrm{X}} \\
& \mathrm{SE}_{3} \%=\frac{\mathrm{A}_{3} / \mathrm{x}_{3} \mathrm{y}}{\text { JKreg }} \underset{\text { EGR }}{\mathrm{X}}
\end{aligned}
$$

\section{HASIL PENELITIAN}

Secara umum hal ini menunjukkan bahwa motivasi belajar dan pemanfaatan internet merupakan faktor yang penting agar diperoleh hasil belajar yang optimal. Dengan adanya motivasi belajar dan pemanfaaan internet, maka akan diperoleh hasil belajar yang tinggi, begitu juga sebaliknya. Besarnya pengaruh motivasi belajar dan peran orangtua terhadap hasil belajar peserta didik secara bersama-sama adalah $51,553 \%$, sedangkan sisanya yaitu $42,66 \%$ ditentukan oleh faktor lain yang mempengaruhi hasil belajar seperti disiplin, kecerdasan, bakat, minat dan perhatian, kesehatan, cara belajar, lingkungan keluarga, lingkungan pergaulan, sekolah, dan sarana pendukung. 
Motivasi ekstrinsik lebih besar dari pada variabel yang lain yaitu memberikan pengaruh sebesar $23,117 \%$ terhadap hasil belajar siswa. Pengaruh motivasi intrinsik terhadap hasil belajar yaitu sebesar $17,975 \%$. Sedangkan pemanfaatan internet sebesar $10,461 \%$ terhadap hasil belajar siswa.

\section{KESIMPULAN}

Berdasarkan hasil penelitian dan pembahasannya, peneliti dapat mengambil kesimpulan sebagai berikut:

1. Berdasarkan hasil perhitungan uji F, Dengan diperoleh nilai $F$ hitung sebesar 34,052 lebih besar dari $\mathrm{F}$ tabel 2,699 dengan probabilitas sebesar $0,000<0,05$. hal ini berarti Ada pengaruh kuat yang signifikan motivasi intrinsik, motivasi ektrinsik dan pemanfaatan internet terhadap hasil belajar siswa kelas VII di SMP Negeri 1 Kapongan.

2. Berdasarkan hasil perhitungan analisa regresi linier ganda, diperoleh koefisien determinasi $\mathrm{R}$ sqr adalah 0,51553 berarti variabel yang dipilih pada variabel independen (motivasi intrinsik, motivasi ektrinsik dan pemanfaatan internet) dapat menerangkan variasi variabel dependen (hasil belajar siswa) dengan kontribusi $51,553 \%$, sedangkan sisanya 48,447\% diterangkan oleh variabel lain.

3. Secara parsial, motivasi ekstrinsik memberikan sumbangan terhadap hasil belajar paling besar dibandingkan dengan motivasi intrinsik dan pemanfaatan internet. Secara parsial sumbangan dari motivasi intrinsik sebesar 17,975\%, motivasi ekstrinsik sebesar $23,117 \%$, dan $10,461 \%$ untuk pemanfaatan internet sekolah.

\section{DAFTAR PUSTAKA}

Arikunto, S. 2011. Prosedur Penelitian: Suatu Pendekatan Praktek. Jakarta: Rineka Cipta.

Darsono, M. 2010. Belajar dan Pembelajaran. Semarang: IKIP Semarang Press

Djamarah, S.B. 2009. Psikologi Belajar. Jakarta: Rineka Cipta.

Hadi, S. 2009. Metodologi Research. Yogyakarta: Andi

Nasution. 2003. Berbagai Pendekatan dalam Proses Belajar dan Mengajar. Jakarta: Bumi Aksara.

Nurseto. T. 2010. Pembelajara Motivasi Berprestasi Dalam Mata Kuliah Kewirausahaan. Jurnal Ekonomi \& Pendidikan. VII. 01. 82-93

Rasyidi, A. H., \& Jaya, N. A. (2019). Penerapan Model Pembelajaran Kooperatif Tipe

Number Head Together. Jurnal Pendidikan dan Kewirausahaan, 6(02), 18-24.

Riyanto, Y. 2010. Metodologi Penelitian Pendidikan, Surabaya: Penerbit SIC

Sardiman. 2011. Interaksi dan Motivasi Belajar Mengajar. Jakarta: PT. Raja Grafindo Persada

Slameto. 2012. Belajar dan Faktor-Faktor Yang Mempengaruhi. Jakarta: Rineka Cipta.

Soemanto. 2010 Psikologi Pendidikan. Jakarta: Rineka Cipta. 
EDUSAINTEK: Jurnal Pendidikan Sains dan Teknologi ～VOLUME 6. No. 1 Mei 2019 ISSN: 1858-005X

Sudjana, N. 2001. Penilaian Hasil Proses Belajar Mengajar. Bandung: Remaja Rosdakarya.

Sugiyono. 2013. Metode Penelitian Pendidikan; Pendekatan Kuantitatif, Kualitatif, dan $R \& D$. Bandung: Alfabeta.

Suryabrata, S. 2012. Psikologi Pendidikan. Jakarta: PT. Grafindo Perkasa

Syah, M. 2010. Psikologi Pendidikan dengan Pendekatan Baru. Bandung: Remaja Rosdakarya 